\title{
AN EPIDEMIOLOGIC STUDY OF HEADACHES IN BRAZILIAN SCHOOLCHILDREN WITH A FOCUS ON PAIN FREQUENCY
}

\author{
Regina Pires de Albuquerque', Adriana Barbosa Santos², \\ Waldir Antônio Tognola', Marco Antônio Arruda ${ }^{3}$
}

\begin{abstract}
The purpose of this study was to assess the prevalence and frequency of the headaches in Brazilian schoolchildren. A cross-sectional study was conducted between March and November 2004 in São José do Rio Preto, São Paulo State, Brazil. A sample of 5,232 children from elementary schools was selected using proportional stratified sampling method. To collect data, a questionnaire was handed out in the schools to the schoolchildren to be answered by parents or guardians. From the total answers received, $84.2 \%$ reported headache complaints during the last year. There were significant complaint differences between males and females. Females were reported as having more frequent headaches than males with daily ones occurring twice as many times. A greater headache frequency was also reported for increasing age. The study has shown that headache prevalence was high, with a predominantly higher frequency (monthly, weekly and daily) with girls and older age groups.
\end{abstract}

KEY WORDS: headache, prevalence, schoolchildren.

\begin{abstract}
Um estudo epidemiológico de cefaléias em escolares brasileiros, com foco sobre a frequência da dor
Resumo - O objetivo deste estudo foi avaliar a prevalência e frequência de cefaléia em escolares brasileiros. Um estudo transversal foi conduzido entre Março e Novembro de 2004 em São José do Rio Preto, Estado de São Paulo, Brasil. Uma amostra de 5.232 crianças das escolas foi selecionada utilizando método de amostragem estratificada proporcional. Para a coleta dos dados, um questionário foi entregue nas escolas aos estudantes para ser respondida pelos pais e/ou responsáveis. Do total de respostas recebidas, $84,2 \%$ relataram cefaléia durante o último ano. Houve diferenças significativas na frequência da queixa de cefaléia entre meninos e meninas. As meninas relataram cefaléias mais frequentes do que os meninos, com prevalência de cefaléias diárias duas vezes maior em meninas. Uma maior frequência de cefaléia foi também relatada com o aumento da idade. $O$ estudo demonstrou que a prevalência de cefaléia foi alta, com uma maior frequência (mensais, semanais e diárias) em meninas e no grupo etário mais velho.
\end{abstract}

PALAVRAS-CHAVE: cefaléia, prevalência, escolares.

Headaches are one of the most common symptoms during childhood and are one of the main complaints in consulting rooms. In many cases the headaches are long lasting and frequent enough to warrant special care.

Since the classic study by Bille ${ }^{1}$, in Sweden, in 1962, several epidemiological studies were undertaken worldwide using the most different types of methodology. These studies suggested a high prevalence of headaches among children and adolescents at varying rates of $20 \%{ }^{2}$ at the age of 5 and up to $97 \%$ in older children and adoles- cents $^{3-11}$. This wide range in the estimate prevalence from several studies results from a number of factors, among which are methodological procedures and age group of the studied population. In one of the few studies done on a Brazilian population, Barea et al..$^{12}$ evaluated 538 students between the ages of 10 and 18 from Porto Alegre, Rio Grande do Sul State, where headache lifetime prevalence rates and in the last year were as high as $93.2 \%$ and $82.9 \%$, respectively.

We present a survey comprising 5,232 children and ad-

'Departamento de Neurologia, Faculdade de Medicina de Rio Preto, Rio Preto SP, Brazil; ${ }^{2}$ Departamento de Ciências da Computação e Estatística, IBILCE-UNESP, São José do Rio Preto SP, Brazil; ${ }^{3}$ Diretor do Instituto Glia, Ribeirão Preto SP, Brazil. 
olescents from the city of São José do Rio Preto (SJRP), São Paulo (SP) State, Brazil, aimed at estimating the prevalence of headaches.

\section{METHOD}

Population

Schoolchildren and adolescents attending Elementary Education in SJRP, SP State, with ages ranging from 6 to 18 years were included in a cross-sectional observational study designed to estimate the prevalence of headache in the municipality.

São José do Rio Preto is a medium-sized city, located in the northwest region of São Paulo State with approximately 414,000 inhabitants. In 2004 the number of schools in SJRP was 54 public and 24 private schools, with 45,663 students enrolled in elementary school ( $1^{\text {st }}$ to $8^{\text {th }}$ grades). The city is subdivided into 14 administrative areas, which were used as reference for selection and location of the participating schools.

\section{Pilot study}

Research phase 1 consisted of a pretest questionnaire to be answered by parents or guardians of the students. Students from two schools - one public and one private - were included in the pretest. The sample comprised 385 students attending elementary school ( $1^{\text {st }}$ to $8^{\text {th }}$ grades). With the adjustments made in the questionnaire, we proceeded to determine the sample size and selection of the schools.

\section{Sampling}

The choice of schools was made by probability sampling using a proportional stratified sampling method with each type of school (public or private) as independent subpopulation (stratum). The first school was chosen at random using a MS Excel 2003 random number generator. Same procedure was used to select the other schools. Then, a random sample proportional to the number of schools in each subpopulation was chosen.

\section{Questionnaire application strategy}

Data collection through questionnaire application was performed from March to November 2004. After consent was granted by the headmaster, the questionnaires were given by one of the project authors to the student's counselor who was made responsible for the distribution and guidance regarding the purposes of the research. The questionnaires, together with the written consent, were taken home by the students and answered by their parents or guardians. Variables analyzed in the questionnaire were as follows: age, gender, ethnic group, and school year (grade), besides four more questions related to the prevalence of headache.

Question 1 - Approximately how many times up to now have you heard your child or adolescent complain of headaches? (very few, sometimes, many times, not once).

Question 2 - When was the last time your child or adolescent complained of headache? (a year or more ago, less than a year ago, he/she never complained).
Question 3 - How many times did your child or adolescent complain of headaches during the last 12 months? (very few times, sometimes, many times, not once).

Question 4 - How often does your child or adolescent complain of headaches? (daily, weekly, monthly, sometimes throughout the year).

\section{Sample}

Thirteen schools were included - 10 public and 3 private - and 8,525 questionnaires were given for students to be answered by their parents or guardians $(6,897$ from public schools and 1,628 from private schools).

\section{Statistical analysis}

Univariate analysis were performed based on descriptive statistics and frequency distribution. Chi-square test $\left(\chi^{2}\right)$ was used to analyze qualitative or categorical variables.

\section{Ethic aspects}

This study was approved by the Local Institutional Ethics Committee of the São José do Rio Preto Medical College. Parents or guardians provided written consent.

\section{RESULTS}

From the 8,525 students included in the sample, 5,232 questionnaires were answered. Of those, 4,254 were attending public schools and 978 private schools. The questionnaire return rate was of $61.4 \% ; 61.7 \%$ from the public schools and $60.1 \%$ from private schools. Analyzing the return percent in relation to the 45,663 children from elementary schools, we achieved a $11.5 \%$ return of the total.

As not everybody in the sample answered all of the questions, percentages presented on the tables above are relative to different subtotals that did so for each question.

Regarding demographic aspects, it was verified that most of the students were female (53.3\%) and white (74.7\%). With regard to school year (grade), 3,138 students (60\%) were attending $1^{\text {st }}$ to $4^{\text {th }}$ grade, whereas 2,093 students (40\%) were attending $5^{\text {th }}$ to $8^{\text {th }}$ grades. Ethnicity also was noted and quantified together with gender and grade in Table 1.

Regarding clinical aspects, the outcome showed that students' lifetime prevalence of headaches was $91.8 \%$ $(4,749)$ while during the last year prevalence was $70 \%(3,624)$.

In relation to students who complained of headaches in the last 12 months, results showed that 2,768 students $(53.7 \%)$ reported having headaches sometimes or many times. The remainder (46.3\%) reported feeling pain very few times, not once, or could not remember. The number of students who did not answer this question was 76.

As for the frequency of pain during the last 12 months, $51.5 \%(2,669)$ students presented headaches sometimes throughout the year, 15.6\% (805) at least once a month, $11.9 \%$ (617) weekly, and 5.2\% (271) daily. It is noted that 
Table 1. Frequency distribution for the following variables: gender, ethnicity and grade.

\begin{tabular}{|c|c|c|}
\hline Variable & Number & $\%$ \\
\hline \multicolumn{3}{|l|}{ Gender } \\
\hline Male & 2,437 & 46.7 \\
\hline Female & 2,786 & 53.3 \\
\hline Subtotal & 5,223 & 100 \\
\hline No answer & 9 & \\
\hline Total & 5,232 & \\
\hline \multicolumn{3}{|l|}{ Ethnicity } \\
\hline White & 3,841 & 74.7 \\
\hline Black & 197 & 3.8 \\
\hline Brown & 1,043 & 20.3 \\
\hline Yellow & 64 & 1.2 \\
\hline Subtotal & 5,145 & 100 \\
\hline No answer & 87 & \\
\hline Total & 5,232 & \\
\hline \multicolumn{3}{|l|}{ Grade } \\
\hline $1^{\text {st }}$ to $4^{\text {th }}$ & 3,138 & 60.0 \\
\hline $5^{\text {th }}$ to $8^{\text {th }}$ & 2,093 & 40.0 \\
\hline Subtotal & 5,231 & 100 \\
\hline No answer & 1 & \\
\hline Total & 5,232 & \\
\hline
\end{tabular}

$32.7 \%$ of the answers were from daily to monthly complaints, corresponding to 1693 students.

\section{Gender-related headaches}

The gender-related headaches were analyzed based on the answers from questions 1 to 4 above mentioned. Results show a statistical difference of the frequency of headaches between boys and girls $(p<0.001)$. While $86.2 \%$ of the female students complained of pain, it was $81.9 \%$ of the male students who complained.
Considering the data related to the episodes occurring during the last year, a statistically significant difference between gender $(p<0.001)$ was verified. Headaches occurred at least once a month (including monthly, weekly, and daily) in $36.6 \%$ of the girls and $28.2 \%$ of the boys. It was further noted that daily headache complaints among girls was almost twice the percentage of that for boys, as can be verified in Table 2 .

Based on answers of second question, a subsample with 1,445 students resulted from the identification of children and adolescents who: answered that they have had headaches for less than a year. The subsample analysis provided the following evidence: girls had headaches more assiduously than boys. As shown in Table 3, while the complaints of the boys are mostly on a monthly basis (54.9\%), the complaints of the girls, total of $57 \%$, are mostly on a daily (18\%) and weekly basis (39\%).

\section{Age-related headache}

Outcomes in Table 4 show that there has been a significant association between the age group of the students and the frequency of lifetime headache. The chisquare test $\left(\chi^{2}\right)$ application revealed that when both age groups were considered - one age group with students from 6 to 11 years and another with students from 12 to 18 years - we could outline both groups presenting different distributions as to the frequency of headache complaints $(p<0.001)$. In the age group ranging from 6 to 11 years old, $32.9 \%$ complained of headache just a very few times, $39.8 \%$ complained sometimes, and $18.1 \%$ complained many times throughout life. In the age group ranging from 12 to 18 years old, the percentage distribution was $26.4 \%$ for the variable "very few times", $42.6 \%$ for "sometimes", and $25.2 \%$ for "many times". From among

Table 2. Frequency and headache complaint during last year according to gender.

\begin{tabular}{|c|c|c|c|c|c|c|}
\hline \multirow[b]{3}{*}{ Frequency } & \multicolumn{4}{|c|}{ Gender } & & \\
\hline & \multicolumn{2}{|c|}{ Male } & \multicolumn{2}{|c|}{ Female } & \multicolumn{2}{|c|}{ Total } \\
\hline & Number & $\%$ & Number & $\%$ & Number & $\%$ \\
\hline Daily & 88 & 3.6 & 183 & 6.6 & 271 & 5.2 \\
\hline Weekly & 237 & 9.8 & 380 & 13.8 & 617 & 11.9 \\
\hline Monthly & 357 & 14.8 & 448 & 16.2 & 805 & 15.6 \\
\hline Subtotal & 682 & 28.2 & 1,011 & 36.6 & 1,693 & 32.7 \\
\hline Sometimes & 1,296 & 53.7 & 1,373 & 49.6 & 2,669 & 51.5 \\
\hline Subtotal & 1,978 & 81.9 & 2,384 & 86.2 & 4,362 & 84.2 \\
\hline Do not have & 335 & 13.9 & 282 & 10.2 & 617 & 11.9 \\
\hline Do not know & 100 & 4.2 & 100 & 3.6 & 200 & 3.9 \\
\hline Subtotal & 2,413 & 100 & 2,766 & 100 & 5,179 & 100 \\
\hline No answer & 29 & & 24 & & 53 & \\
\hline Total & 2,442 & & 2,790 & & 5,232 & \\
\hline
\end{tabular}


Table 3. Frequency of headache complaints according to gender, considering less than one year ago episodes.

\begin{tabular}{|c|c|c|c|c|c|c|}
\hline \multirow[b]{3}{*}{ Frequency } & \multicolumn{4}{|c|}{ Gender } & & \\
\hline & \multicolumn{2}{|c|}{ Male } & \multicolumn{2}{|c|}{ Female } & \multicolumn{2}{|c|}{ Total } \\
\hline & Number & $\%$ & Number & $\%$ & Number & $\%$ \\
\hline Daily & 70 & 11.9 & 155 & 18.0 & 225 & 15.6 \\
\hline Weekly & 194 & 33.2 & 335 & 39.0 & 529 & 36.6 \\
\hline Monthly & 321 & 54.9 & 370 & 43.0 & 691 & 47.8 \\
\hline Total & 585 & 100 & 860 & 100 & 1,445 & 100 \\
\hline
\end{tabular}

Table 4. Frequency distribution of headache complaints according to the age group.

\begin{tabular}{|c|c|c|c|c|c|c|c|}
\hline \multirow[b]{2}{*}{ Headache } & \multicolumn{2}{|c|}{6 to 11 years old } & \multicolumn{2}{|c|}{12 to 18 years old } & \multicolumn{2}{|c|}{ Total } & \multirow[b]{2}{*}{$\mathrm{p}$ value } \\
\hline & Number & $\%$ & Number & $\%$ & Number & $\%$ & \\
\hline \multicolumn{8}{|l|}{ Lifetime } \\
\hline Very few times & 1,199 & 32.9 & 404 & 26.4 & 1,603 & 31.0 & \\
\hline Sometimes & 1,451 & 39.8 & 650 & 42.6 & 2,101 & 40.6 & \\
\hline Many times & 660 & 18.1 & 385 & 25.2 & 1,045 & 20.2 & $0.001^{*}$ \\
\hline Subtotal & & & & & 4,749 & 91.8 & \\
\hline Not once & 334 & 9.2 & 89 & 5.8 & 423 & 8.2 & \\
\hline Subtotal & 3,644 & 100 & 1,528 & 100 & 5,172 & 100 & \\
\hline No answer & & & & & 60 & & \\
\hline Total & & & & & 5,232 & & \\
\hline \multicolumn{8}{|l|}{ During last year } \\
\hline Very few times & 1,109 & 30.6 & 416 & 27.2 & 1,525 & 29.6 & \\
\hline Sometimes & 1,298 & 35.8 & 592 & 38.7 & 1,890 & 36.7 & \\
\hline Many times & 559 & 15.4 & 319 & 20.9 & 878 & 17.0 & \\
\hline Subtotal & & & & & 4,293 & 83.3 & $0.001^{*}$ \\
\hline Not once & 481 & 13.2 & 128 & 8.4 & 609 & 11.8 & \\
\hline Not remember & 181 & 5.0 & 73 & 4.8 & 254 & 4.9 & \\
\hline Subtotal & 3,628 & 100 & 1,528 & 100 & 5,156 & 100 & \\
\hline No answer & & & & & 76 & & \\
\hline Total & & & & & 5,232 & & \\
\hline \multicolumn{8}{|l|}{ During last year } \\
\hline Daily & 172 & 4.8 & 99 & 6.5 & 271 & 5.3 & \\
\hline Weekly & 373 & 10.3 & 234 & 15.4 & 607 & 11.8 & \\
\hline Monthly & 513 & 14.2 & 287 & 18.8 & 800 & 15.5 & \\
\hline Sometimes & 1,936 & 53.5 & 716 & 47.0 & 2,652 & 51.6 & $0.001^{*}$ \\
\hline Subtotal & & & & & 4,330 & 84.2 & \\
\hline Not once & 469 & 13.0 & 142 & 9.3 & 611 & 11.9 & \\
\hline Not remember & 153 & 4.2 & 46 & 3.0 & 199 & 3.9 & \\
\hline Subtotal & 3,616 & 100 & 1,524 & 100 & 5,140 & 100 & \\
\hline No answer & & & & & 92 & & \\
\hline Total & & & & & 5,232 & & \\
\hline
\end{tabular}

p value for chi-square test $\left(\chi^{2}\right)$; ${ }^{*}$ indicates statistically significant differences.

children with ages ranging from 6 to 11 years, 9.2\% did not complain of headaches and the percentage distribution for adolescents was lower (5.8\%). These results suggest that as they get older, the occurrence of lifetime headache complaint also increases.

Table 4 further highlights the results related to headache complaints during the last year. It allows us to pin- point evidences that suggest that age group is an influencing factor on headaches among the students. It can be observed that among children ranging in age from 6 to 11 years, most headache complaints occur a very few times (30.6\%), or sometimes (35.8\%). In the case of adolescents ranging from 12 to 18 years of age, the percentage of headache complaints as the variable "many times" is $5.5 \%$ supe- 
rior to the children's group. Furthermore, it is verified that $13.2 \%$ of the children's report do not have headaches versus $8.4 \%$ among adolescents. A p value $<0.001$ indicates an association statistically significant between the occurrence of headache complaints in the last year and age group.

Regarding the frequency of headache during the last year, the results depicted in Table 4 show that in both students groups, the occurrence of having headache "sometimes" is prevailing ( $53.5 \%$ among children from 6 to 11 years of age vs. $47 \%$ among adolescents from 12 to 18 years of age). However, it is observed that among adolescents, $21.9 \%$ of the complaints occurred on a daily $(6.5 \%)$ and weekly (15.4\%) basis. Among children, $15.1 \%$ complained of pain on a daily and weekly basis. The chi-square test $\left(\chi^{2}\right)$ suggests a statistically significant association between the frequency of headache complaints in the last year and age group $(p<0.001)$.

\section{DISCUSSION}

Our study provides evidence that lifetime prevalence of headache was very high among the students screened. The results are comparable to those reported by Barea et al. ${ }^{12}$, who found a prevalence of $93.2 \%$ among Brazilian students with ages ranging from 10 to 18 years, which is higher than the $75 \%$ at the age of 15 years found in the classic study by Bille?

Concerning headaches during the last year, our results indicate a prevalence of 70\%. A few studies found higher prevalence rates: $92 \%$ in Dutch children and adolescents (from 10 to 17 years) $^{8}$ and $83 \%$ in the Brazilian study ${ }^{12}$. A Turkish study showed a prevalence rate of $53.2 \%$ in adolescents ranging from 12 to 17 years of age ${ }^{11}$, lower than that found in our sample.

Of those who answered having headaches last year, $51.6 \%$ presented headaches only sometimes throughout the year, $15.5 \%$ at least once a month, $11.8 \%$ weekly, and $5.3 \%$ daily. Sillanpaa ${ }^{13}$, in Finland, studied the prevalence of headaches in 2,921 adolescents. During 1981, 69\% of the students at the age of 14 years had headaches presenting the following frequency: $10 \%$ once a month, $5 \%$ weekly, $3 \%$ from 2 to 6 episodes monthly, and 1\% daily. In Holland, Bandell-Hoekstra et al. ${ }^{8}$ evaluating 2,358 students with ages ranging from 10 to 17 years found that nearly all of them reported to have experienced one or more episodes in the previous year. Half of them had headaches at least once a month, including $23 \%$ who had headaches once a week or more.

Laurell et al. ${ }^{9}$, in Sweden, studied 1,371 students from Uppsala with ages ranging from 7 to 15 years and noted that $24.4 \%$ reported to have headaches at least once a week. Lundqvist et al..$^{10}$, in Oslo, studied the prevalence of headaches in 2,126 children from 7 to 12 years of age by means of a diary kept by the children at school over a 6-week period. Of the children who managed to keep the diary, 58\% reported at least one headache episode per month. Furthermore, $19 \%$ of the students had headaches on 7 to 14 days a month and $4 \%$ on 15 days or more than a month, fulfilling the criteria for chronic daily headaches $(C D H)$. It was noted that with these studies the age groups and methodology differed. This may have biased the results showing fluctuations in the prevalence regarding the frequency of headaches.

Despite the differences found concerning the characteristics of the samples in terms of methodological issues, our results are similar to those of Lundqvist et al. ${ }^{10}$ regarding daily headaches, showing that an expressive proportion of children and adolescents had relapsing headaches.

In our study, regarding gender issues, a significant difference related to the complaints between boys and girls was observed. Headaches occurring more frequently are reported by girls. Daily headache complaints among girls are twice as high as the boys' percentile (6.6\% vs. $3.6 \%$, respectively). Similar findings have been reported in other population studies. In these studies, an increasing headache frequency is clearly observed in girls. In the study by Sillanpa ${ }^{13}$, monthly headaches occurred in $19 \%$ of the boys and $24 \%$ of the girls. In a study carried out by BandellHoekstra et al. ${ }^{8}$ weekly headaches were more frequent in girls than in boys ( $24 \%$ vs. $12 \%$, respectively).

Laurell et al. ${ }^{9}$ observed, in their study, that a significant larger number of girls reported weekly headaches ( $28 \%$ vs. $20 \%$ ); the gender difference was more marked in adolescents from 13 to 15 years of age, confirming that as they enter puberty, there is an increased prevalence of headaches in girls. The higher prevalence of headaches occurring more frequently among girls in this study and in the literature emphasizes the importance of taking into consideration headaches as symptom positively dependent on gender ${ }^{12}$.

Regarding age, our sample highlighted that in the age group from 6 to 11 years of age, children had no headache episodes at all, or that headache episodes less frequent were predominant. In the age group from 12 to 18 years of age, children presenting more frequent headaches were prevalent. These results are in accordance with that of other population-based studies showing increased prevalence of headaches with advancing age ${ }^{1,9,11}$.

Our study gives rise to some questions regarding methodological aspects. Among them, it is worth mentioning that we did not make any attempt to collect data from those who did not take part in this research (those who refused to consent or were unable to give written consent). According to Passchier and Olerbeke ${ }^{14}$, no differences were found between participants and absent subjects concerning headache complaints. It may be considered a small selection bias as a consequence of indifference by the research content and/or by not having head- 
ache. In order to reduce such an effect on the results, since this matter involves ethical issues, we sought to collect a sample of a big enough size to achieve a reliable prevalence estimate in this population. Another concern to be taken into consideration is the recall bias that could have happened because headache is an underlying symptom and difficult to be characterized in younger children. In our study, data collection method was performed through a questionnaire answered by parents, next of kin or guardian. Virtanen et al. ${ }^{15}$ did not find any difference regarding headaches as reported by parents and by children. According to Laurell et al. ${ }^{16}$ acceptable correlations were found between parents and children reports in personal interviews, questionnaires, and diaries.

Questionnaires return rate was similar in both public and private schools, showing that the socioeconomic status did not influence the return of the questionnaires. Our study did not take into consideration social status; although a proportional distribution was made related to the number of public and private schools in the sampling method. Deubner ${ }^{17}$ observed in his rationale that there were no differences in headache prevalence in children and adolescents regarding socioeconomic status.

Several studies have been conducted in order to establish the prevalence of chronic daily headaches in adults, but little is known about the prevalence in children and adolescents. In an ongoing study by the Albert Einstein College of Medicine team, quoted by Bigal ${ }^{18}$, in the USA, the overall prevalence of $\mathrm{CDH}$ in adolescents from 12 to 19 years of age was $3.6 \%$, very similar to that found in adults. CDH was more common in girls than boys $(4.6 \%$ vs. $1.2 \%$, respectively, $\mathrm{p}<0.001)$ and increased with advancing age. Of the adolescents with $\mathrm{CDH}, 61.0 \%$ presented great functional disability in daily activities related to study, recreation, and social skills. Bandell-Hoekstra et al. ${ }^{8}$ observed in their study that children and adolescents with more frequent, intensity and long-lasting headaches presented lower quality of life scores, a higher impact on daily and recreational activities, and on family and social skills.

Concerning the questioning about which factors might be related to headaches becoming chronicle in a significant percentage of children and adolescents, changes in society framework and stress increase in this specific age group have been suspected ${ }^{2,13}$.

According to Wober-Bingol ${ }^{19}$, there are multiple ways by which stress and headache can be related. Stress (a) can be a predisposing factor contributing to the onset of a headache; (b) can trigger and exacerbate headache crises, or (c) can accelerate the progression of headaches to a chronic condition.

Further studies should be addresses to develop screening tools which will allow identifying children at risk of chronic headache development.

\section{REFERENCES}

1. Bille B. Migraine in school children. A study of the incidence and shortterm prognosis, and a clinical, psychological and encephalographic comparison between children with migraine and matched controls. Acta Paediatr 1962;136(Suppl1):S151.

2. Sillanppa M, Piekkala P, Kero P. Prevalence of headache at preschool age in an unselected children population. Cephalalgia 1991;11:239-242.

3. Sillanppa M. Changes in the prevalence of migraine and other headache during the first seven school years. Headache 1983;23:15-19.

4. Mortimer MJ, Kay J, Jaron A. Childhood migraine in general practice: clinical features and characteristics. Cephalalgia 1992;12:238-243.

5. Abu-Arafeh I, Russel G. Prevalence of headache and migraine in schoolchildren. BMJ 1994;309:765-769

6. Al Jumah M, Awada A, Al Azzam S. Headache syndromes amongst schoolchildren in Riyadh, Saudi Arabia. Headache 2002;42:281-286.

7. Ayatollahi SMT, Moradi F. Prevalence of migraine and tension-type headache in adolescent girls of Shiraz (Southern Iran). Headache 2002;42:287-290

8. Bandell-Hoekstra IE, Abu Saad HH. Prevalence and characteristics of headache in Dutch schoolchildren. Eur J Pain 2001;5:145-153.

9. Laurell K, Larsson B, Egg-Olofsson O. Prevalence of headache in Swedish schoolchildren, with a focus on tension type headache. Cephalalgia 2004;24:380-388.

10. Lundqvist C, Clench-AAS J, Hofoss D, Bartonova A. Self-reported headache in schoolchildren: Parents underestimate their children's headaches. Acta Paediatrica 2006;95:940-946.

11. Karli N, Akis N, Zarifoglu M, et al. Headaches prevalence in adolescents aged 12 to 17: a student-based epidemiological study in Bursa. Headache 2006;46:649-655.

12. Barea LM, Tannhauser M, Rotta NT. An epidemiologic study of headache among children and adolescents of southern Brazil. Cephalalgia 1996;16:545-549.

13. Sillanpaa M. Changes in the prevalence of migraine and other headache during the first seven school year. Headache 1983;23:15-19.

14. Passchier J, Orlebeke JF. Headaches and stress in schoolchildren: an epidemiological study. Cephalalgia 1985;5:167-176.

15. Virtanen R, Aroma M, Rautava P, et al. Changes in headache prevalence between pre-school and pubertal ages. Cephalalgia 2002;22:179-185.

16. Laurell K, Larsson B, Eeg-Olofsson. Headache in schoolchildren: agreement between different sources of information. Cephalalgia 2003;23: 420-428.

17. Deubner DC. An epidemiologic study of migraine and headache in 1020 year-olds. Headache 1977;17:173-180.

18. Bigal M. Cefaléia crônica diária em crianças e adolescentes. In: Arruda MA, Guidetti V (Eds). Cefaléias na infância e adolescência. Ribeirão Preto: Instituto Glia 2007:137-151

19. Wober-Bingol C. Cefaléia do tipo tensional. In: Arruda MA, Guidetti V (Eds). Cefaléias na infância e adolescência. Ribeirão Preto: Instituto Glia 2007:131-135. 